\title{
The Influence of Theme as Slot Machine Attribute on Casino Gamers Decision-Making
}

\author{
Elizma Wannenburg, Tonie Drotsky and Johan De Jager \\ Department of Marketing, Faculty of Management Siences, \\ Logistics and Sport Management, Tshwane University of Technology, Pretoria, South Africa
}

Received 2012-12-16, Revised 2013-03-06; Accepted 2013-07-02

\begin{abstract}
When entering the casino gaming area, gamers are faced with hundreds of slot machines that vary in terms of themes, colours and sounds. Some gaming situations are characterized by low gamer involvement, but with considerable brand differences. Gamers visiting a casino have the option to play on various types of slot machines. Slot machine games range from single-bar to triple-bar combinations that range in themes and symbols. Some gamers prefer to play on the same slot machine game each time they visit the casino; while other gamers often do slot machine switching. The hypothesis set for this study was to determine if any differences exist between male and female slot machine gamers regarding the way they perceive theme as a slot machine attribute. The sample population identified consists of slot machine gamers busy playing at a specific slot machine in the gaming area of the casino. Cluster sampling was used in the selection of the six South African casinos. A total of six hundred and thirty structured questionnaires were obtained through personal interviews in the gaming areas of the casinos. The raw data collected were statistically analysed on the SPSS program. The main findings of the research indicated that no significant differences exist between male and female slot machine gamers regarding the way they perceive theme as a slot machine attribute. The findings of this study could assist the casino management and slot machine manufacturers in understanding how themes as slot machine attributes influence gamers. By understanding the importance of themes for slot machine gamers can assist casino management and slot machine manufacturers in the development of new slot machines.
\end{abstract}

Keywords: Slot Machine, Gamers, Theme, Casino

\section{INTRODUCTION}

According to Harrigan et al. (2010), slot machine research is a neglected area of exploration for video-game designers and academics. Slot machine manufacturers need to understand the slot machine games that already exist and why they work so well before they develop new games. Game designers can find the answers by observing gamers who enjoy hours of entertainment, interacting with these games in the gaming areas of the casinos. The research was conducted at six selected South African casinos by means of a structured questionnaire. Theme as a slot machine attribute is one of the most important aspects that casino management and slot machine manufacturers must take into consideration when designing new slot machine games. Funk and Ndubisi (2006) note that ever-changing consumer preferences and globalisation contribute to an increasingly competitive market and to a greater need to serve customers better. Casino management and slot machine manufacturers need to stay abreast of new technological changes in order to entice a new clientele by offering high technology games that will satisfy the needs of the gaming market.

\subsection{Research Question}

The question can be asked, "Does male and female casino gamers perceive theme as a slot machine attribute keting, Faculty of Management Siences, Logistics and Sport Management, Tshwane University of Technology, Pretoria, South Africa 
important? To answer this question, the author explored theme and symbols as slot machine attributes. The purpose of this study is to enable casino management and slot machine manufacturers to better understand how slot machine gamers view theme as slot machine attribute in order to develop new slot machine games that will satisfy the needs of the gamers. In the following section relevant literature will be discussed.

\subsection{Slot Machine Symbols and Themes}

The evaluation of the slot machine game choice occurs on entering the casino gaming area, as well as during the time when playing on the slot machine. By observing payouts of other slot machines, or identifying new slot machine games, the gamer might try his or her luck on a different slot machine on the next visit to the casino.

Bennett (2000) states that a slot machine has three rotatable reels, carrying symbols, which are controlled by stepper motors and are arranged to pay out prizes on the occurrence of a predetermined symbol or combination of symbols. Okada (1991) indicated that whether or not a game of a slot machine can result in a hit is determined before the symbol series ever stop moving and preferably, when a start lever is manipulated for starting the motion of the symbol series.

Reid (1986) stated that in the early days of slot machines, only ten out of the twenty symbols could appear on the pay-line of the slot machine. The dummy symbols were effective as "bait", because they often formed winning combinations visible to the player, just above or just below the pay line. Reid (1986) further explained that paying combinations were more likely to appear as near misses, above or below, than as real wins on the pay line itself. According to Asdale (2007), one element of gaming devices that receives considerable attention from game designers is the displayed symbols on the slot machines.

Asdale (2007) further states that the generated symbols are the player's primary focus during the game, because the symbols determine the player's outcome. Poupard (2009) states that the symbols on the slot machine screen are intended to be a distraction from the outside world. Poupard (2009) further implies, that many slot machine gamers become mesmerised by the combination of spinning columns, sound effects and music. Burton (2012) states that technology has made slot machines more fun and entertaining for gamers, but at the same time more complicated.

Themed slot machines 2012 indicates that most slot machines are themed to try to add a bit more interest to the game. Burton (2012) indicates that years ago, most slot machines were the "reel" type; and the gamers had a limited number of choices, such as double diamonds or red, white and blue slot machines. Burton (2012) states that these days, there are hundreds of different slot machine games to choose from. Each one of the slot machines has a different theme with a multitude of symbols on the reels. Poupard (2009) states that the average person might see the slot machine screen as a bunch of characters on spinning columns; but slot machine design psychology plays a major role in the visual impression that gamers receive when looking at a slot machine. SMGT 2012 states that the modern slot machine player is less interested in nostalgia concerning slot machine themes and is more interested in the rise of interactivity in the slot machines. Bennett (2001) notes that gaming manufacturers are keen to devise slot machine games, which are popular with players, as a mechanism for improving sales. Themed slot machines 2012 emphasises that slot machine manufacturers often get their inspiration for slot machine designs from popular films, television shows and pop-culture-based bandits. Slot machine themes 2012 agrees with themed slot machines 2012 and adds that in Star Wars, Batman, Spiderman, the Adams Family and Terminator, the movie is all about those popular slot machine themes favoured by gamers. Wittkowski (2012) states that new server-based slot machine technology will assist casinos in tailoring their slot machine themes just as they wish. With a simple keystroke, computer programmers using a central server will be able to instantly change the themes, minimum bets and payouts at those slot machines. Wittkowski (2012) further states that a software download that usually takes only seconds to complete will replace the tedious manual process now used for changing slot-machine themes.

\section{MATERIALS AND METHODS}

Berndt and Petzer (2011) state that marketing research is a function that is critical for marketing and the success of the organization, because it is focused on making well-informed marketing decisions. Zikmund and Babin (2010) state that basic marketing research is conducted without any specific decision in mind; and it does not usually address the needs of a specific organization. Basic marketing research attempts to expand the limits of marketing knowledge in general; and as such, it is not aimed at solving a particular pragmatic problem. For the purpose of this study, applied marketing research is defined as the systematic collecting, recording, analysis and interpretation of the 
data, to arrive at conclusions and make significant recommendations to solve the problem and accomplish the research objectives.

\section{Hypothesis 1:}

$\mathrm{H}_{03}$ : No significant differences exist between male and female slot machine gamers regarding the way they perceive theme as a slot machine attribute.

$\mathrm{H}_{\mathrm{a} 3}$ : Significant differences exist between male and female gamers regarding the way they perceive theme as a slot machine attribute.

The research design used for this article ensures that the information collected should provide answers to the research question, as well as to resolve the hypothesis and the objectives of the study that were formulated to solve the question at hand. The cluster sampling method was used in this research. Six Sun International casinos, located around South Africa were used in this study. Each selected casino offers table games and slot-machine games as entertainment products to the gamers. For the purpose of this study, the researcher only focused on slot-machine games; and therefore six slot-machine clusters were identified as subgroups: also known as subsets. The subgroups were representative of the population investigated in this study.

The researcher divided each of the six selected gaming areas into four clusters. Each field worker was assigned to a specific cluster area in which to conduct the personal interviews. The researcher used the cluster method, seeing that there was no comprehensive list or sample frame of the population elements that could be used for drawing a random sample. A total number of 630 respondents were interviewed at the 6 selected casinos. Field workers were used to conduct structured interviews with gamers while they were busy playing on a specific slot machine game.

A 5-point Likert scale was utilized to determine gamers attitudes and perceptions regarding the slot machine selection process that they follow. Each statement had a numerical score: (1) strongly disagree, (2) disagree, (3) neither agree nor disagree, (4) agree and (5) strongly agree. A variable was assigned to each statement in the questionnaire. The questions and statements asked in the questionnaire were pre-coded before the questionnaires were completed. Each completed questionnaire was checked in the gaming area of the casino, before the fieldworker issued a new one. Questionnaires that were incomplete were replaced with new ones. The raw data obtained from the questionnaires was edited before it was statistically analyzed with the SPSS statistical software program.

\section{RESULTS}

Burns and Bush (2010) point out that SPSS, the statistical package for the social sciences, is the dataanalysis program most widely used by marketing researchers all over the world. The slot machine selection process that casino gamers follow was statistically analyzed by applying a Chi-square test.

Aaker et al. (2009) state that the chi-square test of independence is valid only if the sample size is large enough to guarantee the similarity between the theoretically correct distribution and the $\mathrm{X}^{2}$ sampling distribution. A significant test was also conducted to either accept or reject the hypothesis set for this study.

Ram (2010) states that the procedure which enables researchers to decide whether to accept or reject a hypothesis is called the test of significance. If the subgroups, male and female, differ in terms of how they perceive the slot machine attributes and the pvalue $=<0.05$, then the null hypothesis would be rejected; and when the p-value is $>0.05$, the null hypothesis would be accepted.

The slot machine gamers had to indicate their favourite slot machine theme. The different slot machine themes from which gamers had to choose were analyzed in Fig. 1. Table 1 gives an overall view of the way gamers perceive the theme as a slot machine attribute

\section{DISCUSSION}

Out of the 630 respondents interviewed at the six casinos 271 were male and 413 were female.

Figure 1 illustrates that $151(24 \%)$ of the 630 slot machine gamers interviewed preferred slot machine theme 1 and $370(58.7 \%)$ theme 2. A total of 373 $(59.2 \%)$ of the gamers liked theme 3 and $306(48.6 \%)$ preferred theme 4 of the 630 respondents, $380(60.3 \%)$ preferred theme 5 and theme 6 was liked by 294 (46.7\%). There were 240 (38.1\%) gamers that preferred theme 7 and $405(64.3 \%)$ favored theme 8 , while 328 $(52.1 \%)$ of the gamers preferred theme 9 and 313 (49.7\%) gamers liked theme 10. Figure 1 reflects that theme 1 and theme 7 were less favored. The five most favored themes were theme 8 , theme 5 , theme 3 , theme 2 and theme 9. The levels of disagreement and agreement between the independent variables, male and female were analyzed. Table 1 gives an overall picture of the levels of agreement and disagreement at the 6 selected casinos. For the purpose of this study, the five-point scale was converted into a three-point scale. The conversion was done due to a number of empty shells, were no responses were given by the respondents. 
Table 1. Levels of agreement and disagreement between male and female slot machine gamers regarding the way they perceive theme as a slot machine attribute

\begin{tabular}{|c|c|c|c|c|}
\hline \multirow[b]{2}{*}{ Variable description } & \multirow[b]{2}{*}{ Three point scale } & \multicolumn{2}{|c|}{ Score by gender $(\%)$} & \multirow[b]{2}{*}{ Results of Chi-Square tests } \\
\hline & & Male & Female & \\
\hline \multirow{3}{*}{ V.1 I have a favourite slot machine theme } & Disagree & 18.9 & 19.1 & Chi-square $=3.731$ \\
\hline & Neither agree nor Disagree & 9.7 & 5.6 & $\mathrm{df}=2$ \\
\hline & Agree & 71.4 & 75.3 & $\begin{array}{l}\text { Sig }=0.155 \\
\text { p-value }=>0.05 \\
\mathrm{H}_{0}=\text { Accepted }\end{array}$ \\
\hline \multirow{3}{*}{$\begin{array}{l}\text { V.2 I prefer to play a slot machine that } \\
\text { reflects my general preferences }\end{array}$} & Disagree & 26.7 & 23.0 & Chi-square $=2.328$ \\
\hline & Neither agree nor Disagree & 15.7 & 20.1 & $\mathrm{df}=2$ \\
\hline & Agree & 57.6 & 56.9 & $\begin{array}{l}\text { Sig }=0.312 \\
\text { p-value }=>0.05 \\
\mathrm{H}_{0}=\text { Accepted }\end{array}$ \\
\hline \multirow{3}{*}{$\begin{array}{l}\text { V3 I would be disappointed if the casino changed } \\
\text { my favourite slot- machine theme to a new one }\end{array}$} & Disagree & 23.0 & 22.5 & Chi-square $=0.723$ \\
\hline & Neither agree nor Disagree & 12.0 & 9.9 & $\mathrm{df}=2$ \\
\hline & Agree & 56.0 & 67.6 & $\begin{array}{l}\text { Sig }=0.697 \\
\text { p-value }=>0.05 \\
\mathrm{H}_{0}=\text { Accepted }\end{array}$ \\
\hline \multirow{3}{*}{$\begin{array}{l}\text { V4 The animations used in slot- machine } \\
\text { themes are of a high quality }\end{array}$} & Disagree & 11.5 & 8.2 & Chi-square $=2.852$ \\
\hline & Neither agree nor Disagree & 10.6 & 8.5 & $\mathrm{df}=2$ \\
\hline & Agree & 77.9 & 83.3 & $\begin{array}{l}\text { Sig }=0.240 \\
\text { p-value }=>0.05 \\
\mathrm{H}_{0}=\text { Accepted }\end{array}$ \\
\hline \multirow{3}{*}{$\begin{array}{l}\text { V5 A slot machine with a rugby theme } \\
\text { would be exciting to play }\end{array}$} & Disagree & 44.7 & 61.3 & Chi-square $=23.933$ \\
\hline & Neither agree nor Disagree & 12.0 & 14.3 & $\mathrm{df}=2$ \\
\hline & Agree & 43.3 & 24.5 & $\begin{array}{l}\text { Sig }=0.000 \\
\text { p-value }=<0.05 \\
\mathrm{H}_{0}=\text { Rejected }\end{array}$ \\
\hline \multirow{3}{*}{$\begin{array}{l}\text { V6 A slot machine with a chess theme } \\
\text { would be enjoyable to play }\end{array}$} & Disagree & 53.9 & 63.0 & Chi-square $=8.134$ \\
\hline & Neither agree nor Disagree & 13.4 & 14.8 & $\mathrm{df}=2$ \\
\hline & Agree & 32.7 & 22.3 & $\begin{array}{l}\mathrm{Sig}=0.017 \\
\text { p-value }=<0.05 \\
\mathrm{H}_{0}=\text { Rejected }\end{array}$ \\
\hline \multirow{3}{*}{$\begin{array}{l}\text { V7 Slot machine symbols that look alike are } \\
\text { difficult to distinguish during pay-outs }\end{array}$} & Disagree & 35.5 & 46.5 & Chi-square $=10.101$ \\
\hline & Neither agree nor Disagree & 17.5 & 10.4 & $\mathrm{df}=2$ \\
\hline & Agree & 47.0 & 43.1 & $\begin{array}{l}\text { Sig }=0.006 \\
\text { p-value }=<0.05 \\
\mathrm{H}_{0}=\text { Rejected }\end{array}$ \\
\hline \multirow{3}{*}{$\begin{array}{l}\text { V8 The theme of a slot machine plays a } \\
\text { role in my slot machine game selection }\end{array}$} & Disagree & 21.2 & 13.1 & Chi-square $=10.204$ \\
\hline & Neither agree nor Disagree & 12.4 & 9.0 & $\mathrm{df}=2$ \\
\hline & Agree & 66.4 & 78.0 & $\begin{array}{l}\text { Sig }=0.006 \\
\text { p-value }=<0.05 \\
\mathrm{H}_{0}=\text { Rejected }\end{array}$ \\
\hline
\end{tabular}

Abbreviations: Sig:- significant differences; df- degrees of freedom

The scales were concerted in order to get a valid statistical analysis of the data and to simplify the statistical analysis. Strongly disagree and disagree were combined, neither agree nor disagree stayed the same and strongly agree and agree were joined. Table 1 gives an overall view of how gamers view them, as a slot machine attribute. 


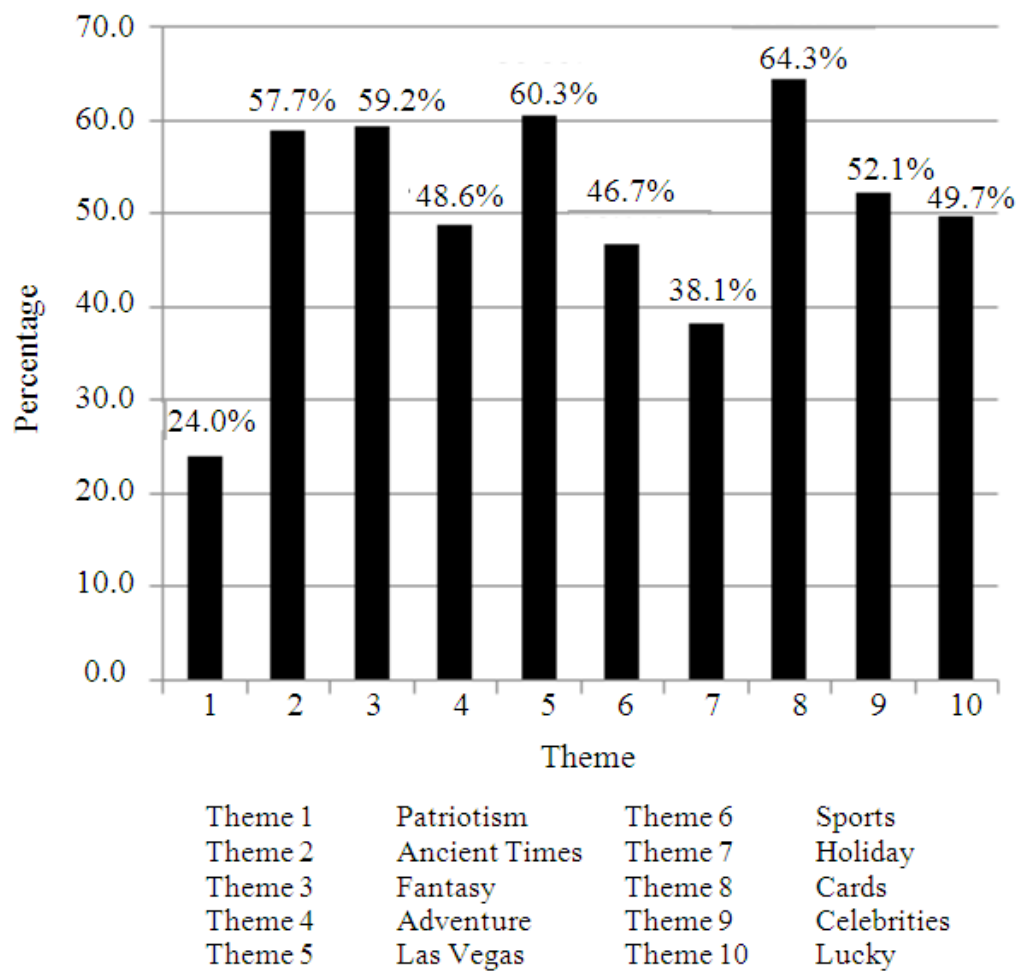

Fig. 1. Slot machine themes

The majority of gamers indicated that they have a favorite slot machine theme and that they prefer to play a slot machine that reflects their general preferences. The farmers also indicated that they would be disappointed if the casino changed their favorite slot machine theme to a new one. The animations used in slot machine themes in the gaming areas are of a high quality while some of the symbols on the slot machines look alike are difficult to distinguish during payout. The gamers indicated that they will not favor a rugby themed slot machine game but a chess themed game would be enjoyable to play on. Most of the gamers indicated that the theme of a slot machine plays a role in their slot machine game selection. Therefore, evidence was obtained for accepting $\mathrm{Ho}_{1}(\mathrm{p}=>0.05)$ for four variables $(\mathrm{V} 1, .2, \mathrm{~V} 3$, $\mathrm{V} 4)$, that no significant differences exist between male and female slot machine gamers regarding the way they perceive them as a slot machine attribute.

Statistical differences existed with four variables (V5, V6, V7, V8), thus $\mathrm{Ho}_{1}(\mathrm{p}=>0.05)$ is therefore rejected for the four variables and $\mathrm{Ha}_{1}(\mathrm{p}<0.05)$ is accepted for the four variables (V1, V2, V3, V4) that significant differences exist between male and female slot machine gamers regarding the way they perceive theme as a slot machine attribute.

\section{CONCLUSION}

Harrel (2012) states that casinos are realizing that newcomers to gambling will soon be looking for more technologically sophisticated games. Casinos want to entice a new clientele by offering all kinds of bells and whistles, including high-tech graphics and sound, as well as games that are geared for player interaction. Casino management and slot machine manufacturers must realize that a new wave of technological evolution has struck the shores of the modern casinos and new innovative games must be incorporated into the gaming areas of the casinos. Casinos need to adapt their customary slot machine games, to into the behavior modification of the gamers, in order to satisfy the needs of the new gaming market. Slot machine manufacturers must design new slot machine games with themes that resemble something with which the slot machine gamers can identify in their everyday life. Casino management must realize that many slot machine gamers build a relationship with some of the machines and the research has indicated that the majority of gamers would be unhappy if the casino were to take away their favorite slot machine. The casino can look at the game play and profits 
of each slot machine in the gaming area, in order to ascertain which ones to keep and which ones to eliminate from the gaming area. Unpopular slot machines could first be moved to a different location in the gaming area and then completely removed from the casino.

\section{REFERENCES}

Aaker, D.A., V. Kumar and G.S. Day, 2009. Marketing Research. 1st Edn., John Wiley and Sons, New York.

Asdale, S.M.V., 2007. Gaming device having symbol stacks. Grant.

Bennett, L.B., 2000. Slot machine with color changing symbols. Grant.

Bennett, N.L., 2001. Slot machine game with randomly designated special symbols. Grant.

Berndt, A. and D. Petzer, 2011. Marketing Research. Pearson Education Ltd, South Africa.

Burns, A.C. and R.F. Bush, 2010. Marketing Research. 6th Edn., Pearson, Global, USA., pp: 01.

Burton, B., 2012. Visual culture isn't just visual: Multiliteracy, Multimodality and meaning.

Funk, D. and N.O. Ndubisi, 2006. Colour and product choice: A study of gender roles. Manage. Res., 29: 41-52. DOI: $10.1108 / 01409170610645439$
Harrel, L., 2012. New trends in slot machines for a new generation.

Harrigan, K.A., K. Collins and M.J. Dixon, 2010. Addictive gameplay: What casual game designers can learn from slot machine research. Proceedings of the International Academic Conference on the Future of Game Design and Technology, May 0607, ACM Press, Vancouver, BC, Canada, pp: 127133. DOI: $10.1145 / 1920778.1920796$

Okada, K., 1991. Slot machine. US patent 5,024,439.

Poupard, L.V., 2009. Slot Machine Design Psychology 101. Yahoo! Inc.,

Ram, B., 2010. Engineering Mathematics. 1st Edn., Pearson Education India, New Delhi, ISBN-10: 8131726916.

Reid, R.L., 1986. The psychology of the near miss. J. Gambling Behav., 2: 32-39. DOI: 10.1007/BF01019932

Wittkowski, D., 2012. Server-Based Slot Machines that can Change Themes Instantly set to Debut at Revel's casino in Atlantic City.

Zikmund, W.G. and B. Babin, 2010. Exploring Marketing Research. 10th Edn., China, SouthWestern Cengage Learning, ISBN-10: 0324788444, pp: 736 . 